\title{
Desórdenes en la Provincia franciscana de Valencia a finales del siglo XVII
}

\author{
Emilio Callado Estela \\ Universidad CEU-Cardenal Herrera. Valencia \\ ecallado@uch.ceu.es
}

Recibido: 29 de marzo de 2011

Aceptado: 7 de febrero de 2013

\begin{abstract}
RESUMEN
El presente artículo analiza la inestabilidad padecida a finales del siglo XVII por la Provincia franciscana observante de Valencia. La gravedad de la situación retrotrajo a los hijos de san Francisco a tumultuosos tiempos pasados, ante la mirada cómplice de las autoridades superiores de la orden. El recurso a la nunciatura complicaría todavía más este conflicto, enfrentando a la jurisdicción eclesiástica con la lugartenencia general del reino mientras el conflicto se extendía a los seglares y amenazaba seriamente el orden del territorio. Sería al final la corona, con la concurrencia de la Santa Sede y mediante el enarbolamiento de sus regalías sobre la Iglesia, quien atajara la crisis.
\end{abstract}

Palabras clave: Franciscanos, Valencia, Siglo XVII, Conflictividad.

\section{Disorders in the Franciscan Province of Valencia towards the end of the 17th century}

\begin{abstract}
The present article analyses the instability the Franciscan province of Valencia suffered at the end of the 17th century. The seriousness of the circumstances took the followers of saint Francisco back to uproarious past times, with the connivance of the order's higher authorities. The appeal lodged by the nunciature made this conflict even more complicated and confronted the ecclesiastic jurisdiction with the general vice regency of the reign while the conflict spread over to the laity and seriously menaced the order of the territory. Eventually the crown put an end to the crisis through the concurrence of the Vatican and hoisting its royalties over the Church.
\end{abstract}

Key words: Franciscans, Valencia, 17th Century, Conflictivity. 


\section{Introducción}

La conflictividad interna de las órdenes regulares constituye un problema casi tan antiguo como su propia historia ${ }^{1}$. En las crónicas de las distintas familias religiosas es frecuente hallar eco de tales disputas. Tampoco en la documentación archivística escasean referencias de esta índole. Maneras encontradas de entender la regla, la lucha por el poder e incluso motivaciones mucho más triviales turbaron demasiado a menudo la paz del clero regular contribuyendo a la decadencia de la vida religiosa. El siglo XVII, al menos para la Monarquía Hispánica, fue pródigo en estos episodios. Tanto que, según A. Domínguez Ortiz, apenas se libró de ellos ninguna orden, excepto la Compañía de Jesús, por su régimen autoritario ${ }^{2}$. Las restantes exhibirían sus miserias con ocasión de la celebración de capítulos y congregaciones, en que los diferentes bandos o facciones se materializaban para hacerse con el control y repartirse los cargos. No era inusual que los ecos de estas batallas trascendieran fuera de los claustros y que los fieles tomaran partido en la contienda, como tampoco la intervención de la corona para restablecer la $\mathrm{paz}^{3}$.

Algo así ocurrió en la Provincia franciscana observante de Valencia durante los últimos años del Seiscientos, etapa de esta religión ignorada por la historiografía reciente todavía más que el resto de la centuria y el conjunto de la época moderna, ya de por sí desatendidos en el levante peninsular por la escasa tradición de tales estudios y la destrucción de buena parte de los archivos de la orden como consecuencia de los desastres bélicos y las convulsiones políticas de la contemporaneidad ${ }^{4}$. En la línea de lo ocurrido en otros territorios de la Corona de Aragón ${ }^{5}$, desde su llegada a estas latitudes, en la decimotercera centuria, la trayectoria de los franciscanos no había estado exenta de sobresaltos internos ${ }^{6}$. Entre los más recientes y conocidos podrían citarse aquellos suscitados por el estertor de los claustrales o la aparición de la recolección, en el siglo

1 Véanse al respecto las páginas dedicadas al tema por Martínez Ruiz, E. (dir.): El peso de la Iglesia. Cuatro siglos de órdenes religiosas en España, Madrid, ACTAS, 2004, especialmente 264 y ss.

2 Domínguez Ortiz, A.: “Aspectos sociales de la vida eclesiástica en los siglos XVII y XVIII", en GARCíAVillosladA, R.: (dir.), Historia de la Iglesia en España IV. La Iglesia en la España de los siglos XVII y XVIII, Madrid, BAC, 1979, p. 53.

3 Barrio Gozalo, M.: El clero en la España Moderna, Córdoba, Caja Córdoba, 2010, pp. 365-374.

4 Situación que contrasta con el nivel actual de conocimientos alcanzado por la historia de los hijos de san Francisco en otros lugares de la Monarquía Hispánica. Sólo a modo de ejemplo, véase el caso andaluz, a través de iniciativas como los cursos de verano reunidos en Córdoba desde 1995, origen de más de una decena de volúmenes sobre el franciscanismo en Andalucía, coordinados por M. Peláez del Rosal y publicados por la Universidad de Sevilla. Un estado general de la cuestión en Graña Cid, Ma. M. y Boadas Llavat, A. (coords): El franciscanismo en la Península Ibérica. Balance y perspectivas, Madrid, GBG Editora, 2005, y FERNÁNDEZGallardo JimÉnez, G. (coord.): Los franciscanos conventuales en España, Madrid, GBG Editora, 2006.

5 Hebrera Y Esmir, J. A.: Chrónica seráfica de la santa Provincia de Aragón de la regular observancia de nuestro padre san Francisco, Zaragoza, Diego de Sarvembe, 1703-1705, 2 vols, y MARCA, F.: Crónica de la Provincia franciscana de Cataluña, Madrid, 1764. De ambas existen recientes ediciones facsimilares.

6 Pueden seguirse a través de la páginas de Martínez Colomer, V.: Historia de la Provincia de Valencia de la regular observancia de San Francisco, Valencia, Salvador Fauli, 1803 De esta obra existe una nueva edición, a cargo del padre B. Agulló Pascual, publicada en Madrid, por Cisneros, el año 1982. Citaremos por la primera. 
anterior ${ }^{7}$. Desde entonces, y a falta de nuevas investigaciones que puedan corroborar lo contrario, la tranquilidad parecía haberse instalado en la cotidianeidad seráfica, interrumpida de modo esporádico por algún incidente, con mayor o menor trascendencia, cuyo recuerdo se pierde entre las páginas de la historia oficial de la orden.

Sin embargo, por razones nada claras que las fuentes documentales conservadas silencian, a partir de 1694 los franciscanos valencianos volverían a verse inmersos en una espiral de inestabilidad, prolongada durante algo más de un lustro. La gravedad del asunto retrotrajo la Provincia a tumultuosos tiempos pasados ante la mirada cómplice de sus autoridades superiores, incapaces de actuar en un único sentido. El recurso a la nunciatura complicaría todavía más este trance, enfrentando a la jurisdicción eclesiástica con la lugartenencia general del reino de Valencia mientras el conflicto se extendía a los seglares y amenazaba seriamente la estabilidad del territorio. Tuvo que ser al final la corona, con la concurrencia de la Santa Sede y mediante el enarbolamiento de sus regalías sobre la Iglesia, quien recondujera la situación hasta el punto de partida. Habrían de transcurrir antes seis intensos años, de disturbios, destierros y encarcelamientos, con el consiguiente deterioro para la imagen y reputación de los hijos de San Francisco.

De todo ello nos ocupamos a partir de las exiguas noticias proporcionadas por las crónicas seráficas, no tanto las generales, que pasarían por alto el episodio, como las locales $^{8}$, casi nunca imparciales ambas en este tipo de cuitas internas. Por suerte, para contrastarlas, hemos contado con la abundante información sobre el caso contenida en decenas de cartas, consultas y memoriales originales, conservados no en los archivos de la orden, muy castigados en este ámbito geográfico, como se ha dicho, sino en el de la Corona de Aragón 9 . Una buena oportunidad, en fin, para empezar a recuperar la historia de la Provincia franciscana observante de Valencia durante la modernidad.

\section{Fray Jaime Vitoria, ¿ángel o demonio?}

Capítulos y ministros provinciales comprometidos con la observancia regular, "para conducir siempre a esta Provincia a la más alta perfección", según el relato oficial de

7 Seguí Cantos, J.: "La reforma franciscana en Valencia: los recoletos (1581-1583)", Archivo Iberoamericano, 237 (1993), pp. 423-448.

8 En este caso hablamos, particularmente, de la Historia del padre Martínez Colomer más arriba mencionada, la única de las crónicas de este tipo llegadas hasta nuestros días. Existieron otras, no obstante, quizá perdidas para siempre, como por ejemplo: Insa, J.: Historia de la Provincia de Valencia de la orden de san Francisco (1607), SÁnchez del Castellar, G.: Crónica de todas las cosas memorables que desde el principio ha tenido esta Provincia de Valencia, sacada de todos los documentos antiguos que estaban en el Archivo de la Provincia (1635), Guardiola, L.: Memorias históricas de la Provincia de Valencia (1644), Sorribas, J.: Historia seráfica de la santa Provincia de san Francisco de Valencia (1740). Véase al respecto Ivars, A.: "Cronistas franciscanos de la Provincia de Valencia", Archivo Ibero-americano, 28 (1927), pp. 263271 y 378-386, y 31 (1929), pp. 387-402. También SAnz VALdivieso, R.: “Crónicas franciscanas españolas (bibliografía) hasta el siglo XIX”, en Graña Cid y Boadas Llavat (coords), op. cit. (nota 4), pp. 41-70.

9 Concretamente en los legajos 695 y 696 de la sección Consejo de Aragón. Secretaría de Valencia. Pese a las pesquisas operadas, ni un solo rastro sobre el caso ha sido localizado en el Archivo Histórico Nacional. SAnz de Bremond y Mayans, A.: “Aproximación al estudio del franciscanismo en la Corona de Aragón. Los documentos del Archivo Histórico Nacional”, Cuadernos de Historia Moderna, 32 (2007), pp. 137-158. 
los hechos, se habrían sucedido monótonamente entre los franciscanos de Valencia desde mediados del siglo XVII hasta el segundo mandato al frente de los mismos de fray José Feliu, hombre "de vida austera, aspecto grave, conducta exemplar, costumbres suaves y ciencia nada vulgar" repentinamente decidido a retirarse del mundo. "Y como viese además que la Provincia se iba enmarañando", con el resurgimiento de parcialidades y bandos frailunos en teoría superados, sorprendió a todos presentando su renuncia al cargo ante el definitorio reunido el 27 de octubre de 1694, en el valentino convento de San Francisco, bajo la presidencia del padre Jacinto Hernández de la Torre, comisario general de la orden para la familia ultramontana ${ }^{10}$. De los tres candidatos propuestos por éste para guiar los destinos de la Provincia hasta la convocatoria del próximo capítulo provincial, para el que todavía restaban dos años, resultó ser elegido por una mayoría de votos fray Jaime Vitoria.

El nuevo vicario provincial, natural de Dénia, era ex-lector de Filosofía, antiguo guardián de Oliva y en la actualidad de Valencia. Un religioso ejemplar, a decir de los cronistas franciscanos, entregado desde entonces en cuerpo y alma al ministerio para el que le habían escogido sus hermanos de hábito

Era sugeto de egregias qualidades, lleno de nobleza y de grandeza de alma y a quien las vicisitudes de la Fortuna, que le fue harto inconstante, jamás pudieron abatir. Había exercido ya con honor el empleo de custodio y gozaba el título de padre de la Provincia de Mallorca. Se dedicó constantemente a sostener la disciplina regular en todos sus conventos ${ }^{11}$.

La cruda realidad, sin embargo, empañaría esta visión edulcorada del padre Vitoria, viejo conocido en los tugurios de la capital valentina desde sus tiempos de lector, en que anduvo desterrado en Morella por sus demasías con el sexo opuesto, "y en lugar de corregirlas, en aquella áspera región, las acreditó con mayor escándalo, entrando muy freqüentemente en cassa de unas mujeres". A juzgar por los testimonios de un reputado ministro de la Real Audiencia, fray Jaime no abandonó tales costumbres tras su elección como vicario provincial. En más de una ocasión, fue sorprendido en situaciones comprometidas; fuera en plena calle, "ablando y haciendo demostraciones indecentes con dos mugeres", o en domicilios particulares con alguna esposa, "sin ábitos y en traje de estarle ofendiendo su honrra". Solía acompañarle en muchas de estas veleidades su hermano Vicente, canónigo de la colegiata de Xàtiva, otro eclesiástico de escaso recato moral -más conocido hasta ahora por sus dotes pictóricas

10 El origen de esta responsabilidad se remontaba al siglo anterior, en que la entronización del LXIV ministro general de la orden había ratificado la alternancia establecida en la cúspide seráfica entre sus dos grandes familias, cismontana y ultramontana; alternancia muy pronto repartida entre españoles e italianos. Semejante práctica suponía que, de corresponder el turno a una de las partes, la otra era regida por un comisario - ahora el padre de la Torre y poco después fray Antonio Folch de Cardona- que prácticamente hacía las veces de ministro general en su territorio. Carbajo, D., Elementos de Historia de la orden franciscana, Tipografía San Francisco, Murcia, 1958, p. 98.

11 Martínez Colomer, op. cit. (nota 6), p. 424. 
que le hicieron vivir entre Valencia y Roma ${ }^{12}$ - cuyos flirteos con señoras ajenas le habían valido algún que otro carabinazo a manos de varios maridos despechados ${ }^{13}$.

Con semejante expediente en su haber, no parece que fray Jaime fuera la persona más idónea para ocuparse de ninguna responsabilidad en la orden. De hecho, los “enmarañamientos" vislumbrados entre los franciscanos durante el mandato de su predecesor, cobraron tal intensidad que en pocos meses fracturaron la Provincia. Un grupo de frailes hicieron llegar entonces sus quejas contra la mala vida del padre Vitoria al nuevo comisario general. Hablamos del valenciano fray Antonio Folch de Cardona, hombre de aquilatada experiencia en el gobierno seráfico ${ }^{14}$.

Hijo natural de don Felipe Folch, marqués de Guadalest, y de "una señora noble", este religioso había venido al mundo en 1657. En la localidad de Ondara transcurrirían su infancia y adolescencia hasta que, muerto su padre, se trasladara a la corte con apenas quince años. De su primer oficio como capitán de la infantería real, en las campañas de Portugal, pasó a abrazar la vida consagrada en la Provincia de la Concepción ${ }^{15}$. En el convento palentino de San Francisco tomó el hábito e hizo el noviciado. Una beca le permitió marchar con posterioridad al colegio mayor de San

12 Considerado por algunos autores pariente remoto de san Vicente Ferrer, se había formado en el Estudi General valentino. Viajaría con posterioridad a Italia para perfeccionar su técnica junto al reputado artista Carlo Marati. Durante su primera estancia romana obtuvo un canonicato en la colegiata de Xàtiva, si bien, de vuelta a la España, continuaría residiendo en Valencia, ejecutando toda suerte de encargos para ornato de iglesias y conventos de la órbita franciscana, a la par que profundizaba en el estudio de la antigüedad clásica. A comienzos del nuevo siglo regresó a la Ciudad Eterna, admitiéndosele en la célebre Academia de los Arcades fundada por la reina Cristina de Suecia. Llegó a ejercer como anticuario de Clemente XI y pintor de cámara del Gran Duque de Toscana, hasta su fallecimiento, acaecido en 1712. Dejó escritas varias obras, particularmente Vita è miracoli dell'apostolo valenciano San Vincenzo Ferreri, dell'ordine de Predicatori, Roma, 1705, Observazioni sopra il libro della Felsina pitrice, e Historia pittoresca. Ximeno, V.: Escritores del Reyno de Valencia chronológicamente ordenados desde el año MCCXXXVIII de la christiana conquista de la misma ciudad hasta el de MDCCXLVIII, Valencia, Librerías París-Valencia, 1980, vol. II, pp. 164-165, y Orellana, M. A.: Biografía pictórica valentina o vida de los artistas valencianos, Valencia, Librerías ParísValencia, 1995, p. 204.

13 Archivo de la Corona de Aragón (ACA), Consejo de Aragón. Leg. 696, doc. 70/66. El testimonio corresponde a don Vicente Monserrat Crespí de Valldaura, juez de corte u oídor de causas criminales de la Audiencia valentina. CANET ApARISI, T.: La Magistratura valenciana (s. XVI-XVII), Valencia, Alfons el Magnànim, 1990, p. 184.

14 Pastor Fuster, J.: Biblioteca valenciana de los escritores que florecieron hasta nuestros días y de los que aún viven, Valencia, Librerías París-Valencia, 1980, vol. II, p. 14. A la espera de una biografía completa sobre este personaje, que parece resistirse, hemos de conformarnos con los siguientes estudios: OLMos CAnAlda, E.: Los prelados valentinos, Madrid, Inst. Jerónimo Zurita, 1944, pp. 224-228; PÉrez ApARICIO, C.: "El clero valenciano a principios del siglo XVIII. La cuestión sucesoria", en Estudios de Historia de Valencia, Valencia, Universitat de València, 1978, 252-278; Pradells NADAL, J.: "Notas sobre los orígenes de la Biblioteca Nacional: las bibliotecas del arzobispo de Valencia Antonio Folch de Cardona", Revista de Historia Moderna. Anales de la Universidad de Alicante, IV (1984), pp. 149-187; GARCía GómEZ, Mª D.: El arzobispo de Valencia Folch de Cardona. Análisis de una biblioteca eclesiástica del siglo XVIII, Alicante, Universidad de Alicante, 1996; León SAnZ, V.: "Fray Antonio Folch de Cardona, un arzobispo valenciano en la Presidencia del Consejo de España en Viena", en E. Callado Estela (coord.): Valencianos en la Historia de la Iglesia III, Valencia, Facultad de Teología San Vicente Ferrer, 2009, pp. 103-148; y CALLAdo Estela, E.: "Del convento a la mitra pasando por la corte. Los años ignotos del arzobispo de Valencia fray Antonio Folch de Cardona" (en prensa).

15 Alonso, M.: Chrónica seráphica de la santa Provincia de la Puríssima Concepción, Valladolid, Imprenta de la Real Chancillería, 1734, pp. 349-350. 
Pedro y San Pablo, en Alcalá de Henares, donde permaneció entre 1684 y $1685^{16}$. Leyó más tarde Teología en las aulas conventuales abulenses durante algo menos de un trienio. De regreso a Palencia, ejerció como guardián otros tres años, hasta ser elegido ministro provincial, último de sus empleos antes de convertirse el 2 de febrero de 1696 en comisario general de la familia ultramontana de la orden y -algo después- de la Indias occidentales ${ }^{17}$.

Como tal, el padre Folch de Cardona hizo suyas las denuncias llegadas desde la Provincia de Valencia, implicándose de lleno en la pacificación de la misma desde su privilegiada posición en la corte carolina, junto al Almirante de Castilla don Juan Tomás Enríquez de Cabrera y Toledo, hombre de confianza de la reina doña Mariana de Neoburgo ${ }^{18}$. La gestión de este episodio, sin duda, marcaría el mandato del religioso de principio a fin, arruinando con toda probabilidad su promoción a más altos destinos en el organigrama del gobierno seráfico.

Por ahora, el comisario general se trasladó hasta Alicante para presidir el capítulo provincial previsto para octubre de 1696 en el convento de Santa María de Gracia. Antes se detendría en Valencia, donde el día 9 de aquel mes encargaba a su secretario personal, fray José de Avaroa, indagara extraoficialmente sobre los vicios del vicario provincial allí residente. Once días de pesquisas y los testimonios de seis testigos bastarían para confirmar la reiterada transgresión del voto de castidad por parte del padre Jaime Vitoria, algunas otras de sus feas costumbres y el impacto de todo ello para la armonía de la Provincia.

Fray Antonio tuvo conocimiento de los resultados de esta investigación en la capital alicantina el 28 de octubre, a unas horas tan sólo de inaugurarse el capítulo provincial. Con el expediente del vicario provincial saliente sobre la mesa del comisario general pendiente de tramitación, dos religiosos medirían sus fuerzas como posibles ministros provinciales: el candidato oficial fray Vicente Pérez, avalado por el mismo padre Folch de Cardona, y fray Juan Bautista Todo, lector jubilado de Teología y hechura de fray Jaime Vitoria, presente en el cónclave. La mayoría de sufragios fueron a parar a manos de este último en un clima de enfrentamiento abierto entre los partidarios de uno y otro aspirante. De muy poco servirían las llamadas a la calma del nuevo superior provincial, que en su toma de posesión prometió aplicarse "con todas nuestras fuerzas a restablecer la [paz], castigando con exemplares escarmientos a sus perturbadores..." 19

16 Alcolea, N.: Seminario de nobles, taller de venerables y doctos, el colegio mayor de San Pedro y San Pablo fundado en la Universidad de Alcalá de Henares para trece religiosos de todas las Provincias observantes de nuestro padre san Francisco de estos reynos por el eminentísimo y venerable cardenal de España, mi señor, don fray Francisco Cisneros, Madrid, Imprenta y librería de don Manuel Martín,1777, p. 314, y Uribe, A.: Colegio y colegiales de San Pedro y San Pablo, Madrid, Cisneros, 1981, p. 206.

17 En este último caso por letras patentes del ministro general despachadas el 4 de marzo de 1697. ArRoYo, L.: "Comisarios generales de Indias", Archivo Ibero-americano, 47 (1952), pp. 269-270. Más detalles en Memoria de los padres comissarios generales que nuestra Provincia de Castilla ha tenido en los reynos del Perú y México, en Archivo Franciscano Ibero-Oriental (AFIO). Ms. B-125, Álvarez, D.: Chrónica seráfica de la Provincia de Castilla de la Regular Observancia, ff. 158v- 160.

18 Contreras, J.: Carlos II el Hechizado: poder y melancolía en la corte del último Austria, Madrid, Ariel, 2003 , pp. 245 y ss.

19 Cit. Martínez Colomer, op. cit. (nota 6), p. 426. 
Tampoco contribuirían a sosegar los ánimos las letras despachadas el 2 de noviembre por el comisario general poco antes de regresar a la corte. Según éstas, el padre Vitoria debería permanecer en el convento de Alicante, "sin salir a otro lugar alguno, más que a dicha ciudad, ni pasar a otro convento alguno de la Provincia", en tanto se iniciaba en Valencia un proceso criminal formal contra su persona a cargo de un par de comisarios delegados para el caso $^{20}$.

Durante algunas semanas el antiguo vicario provincial no abandonó Santa María de Gracia, hasta que el 26 de noviembre, con la excusa de visitar el vecino convento de Nuestra Señora del Carmen, escapó a la Capital del Turia, con la consiguiente declaración de apostasía y excomunión reservada por los estatutos franciscanos a los frailes desobedientes. Refugiado en casa del Castellán de Amposta y bajo la protección del ministro provincial, buscó el auxilio de influyentes personajes para que intercederían por él ante el nuncio apostólico don José Archinto, a quien el religioso solicitó autorización para marchar a Roma y denunciar al ministro general la persecución a la que estaba sometido por parte de fray Antonio Folch de Cardona, amparado por los amigos de la reina. A comienzos de 1697 la nunciatura declinaba esta petición ante las presiones del comisario general y el Almirante de Castilla. Hubieron de mediar todavía los padres Andrés Caperó, carmelita ${ }^{21}$, y Juan Nolasco Risón, de la Mer$\mathrm{ced}^{22}$, con gran predicamento ambos en el mundo eclesiástico valenciano finisecular, para que fray Jaime reconociera su desacato y se pusiera a disposición de las autoridades franciscanas en el convento de la Corona, donde fue absuelto de las censuras que le habían sido impuestas con la condición de regresar a Santa María de Gracia.

Efectivamente, el religioso volvió a Alicante, pero no a su encierro, sino al domicilio del cónsul de Inglaterra. Allí aguardó refugiado hasta que pudo trasladarse a Dénia y embarcarse para Italia. Llevó consigo una decena de credenciales que avalaban su buena conducta. En ellas, se atribuían cuantos yerros le achacaban al comisario general, "enemigo de fray Jaime Vitoria por causa de no haber asentido a su dictamen en la elección del capítulo provincial último y haberle frustrado la elección", y a su secretario fray José de Avaroa, "tan enemigo declarado suio como lo manifiesta la maldición que le hechó al padre Vitoria con estas palabras: Obsecro Deipare Virgini ipsum corpore et anima a Demonibus movere..."23

Una vez en Nápoles, el virrey duque de Medinaceli facilitaría al franciscano un pasaporte para llegarse sin problemas hasta Roma y pleitear personalmente su causa, valiéndose para ello de las amistades y contactos de su hermano Vicente en aquella ciudad sin que fray Antonio Folch de Cardona pudiera impedirlo. Aún trataría de evi-

20 ACA, Consejo de Aragón, Leg. 696, doc. 70/2.

21 Este insigne fraile había sido lector de Artes y Teología, dos veces prior del convento de Onda y otras dos en el de Valencia, provincial, asistente del padre general para las Provincias de España, procurador y vicario general de toda la orden del Carmelo. Tuvo a su cargo varias embajadas encomendadas por los estamentos del reino. En 1714 Felipe V le promovía al obispado de Lugo y cuatro años después al de Teruel, que gobernó hasta su muerte acaecida unos meses más tarde. XIMENO, op. cit. (nota 9), vol. II, pp. 176-177.

22 Maestro en Artes, doctor en Teología y catedrático de Metafísica en el Estudi General valentino, compaginó el desempeño de importantes responsabilidades en el seno de su orden, como definidor o provincial, con otras de carácter más político como miembro del estamento eclesiástico del reino, del que fue diputado y juez de contrafueros. Falleció en 1700. Ibidem, pp. 134-135.

23 ACA, Consejo de Aragón. Leg. 695, docs. 33/6- 33/7. 
tar éste, sin embargo, que la Sagrada Congregación de turno diera la razón al antiguo vicario provincial de Valencia, como hizo ver a Carlos II, pues

por la excesiva piedad de aquel Tribunal y el común concepto que han formado de que la dominante y tirana altivez de los superiores ultraja sobradamente a los pobres súbditos regulares, en cuia suposición, desatendiendo los méritos de las causas, persuadidos a que la plenitud de sus probanzas la dispuso el juez con su apasionada industria, vuelven indefectiblemente absueltos todos los que hacen tales recursos, en que no sólo padece gravemente la justicia, sino que se dexa totalmente exarmado al superior de su jurisdicción y expuesto a una destención universal ${ }^{24}$.

Particularmente grave sería que esto acabara ocurriendo con fray Jaime Vitoria, cuyas faltas parecían no conocer arrepentimiento pese a la paciencia mostrada hasta entonces por los superiores de la orden. Antes al contrario, como detalló pormenorizadamente el padre Folch de Cardona

había motivado gravíssimos escándalos y cometido enormes delitos pocos meses antes que fuesse electo en [vicario] provincial de dicha Provincia, siendo actual guardián de el convento principal de la ciudad de Valencia, y que era perjudicialíssima esta tolerancia, pues por haberla tenido sobradamente paciente otros superiores con este fraile, perdonándole una apostasía que hizo, siendo letor de Filosofía, y otros muchos delitos que cometió siendo guardián en el convento de Oliva y continuó después en diferentes partes, con grave cargo de su conciencia, se insolentó más cada día, desfigurando sus vicios de tal suerte que, siendo públicos, tuvo habilidad para disponer no los comprehendiesse nuestro antezessor y concurriesse a elegirle [vicario] provincial, en cuia ocupación pudo con más libertad soltar las riendas a su mala inclinación, con la mayor ruina de la misma Provincia ${ }^{25}$

No habría paz en la Provincia franciscana de Valencia, concluía su exposición el comisario general, en tanto religiosos como fray Jaime, quizá de los peores a quienes había tenido la desdicha de conocer, continuaran campando a sus anchas

es cabeza de una poderosa parcialidad de su Provincia, de que se halla assistido; de grande habilidad, genio ardiente y astuto; natural vengativo y de el mayor desembarazo, que precisamente crezerá rotos los términos de el temor a sus prelados, pues vuelve triunfante contra todos. Y hallándose ofendido de los más de la opuesta parcialidad, de quien presume le a ocasionado esta persecución, fácilmente se dexa comprehender quánto obrará para satisfacer su odio y rencor. Y siendo tan notoria la condición de aquellos naturales [del reino de Valencia], propensos a la discordia, se haze muy perceptible las graves ruinas a que se expondría aquella Provinçia ${ }^{26}$.

Todo lo cual justificaría que fray Antonio le declarara "por apóstata, descomulgado, fugitivo e inobediente" el 14 de enero de 1697, ordenando a todos los guardianes de la Provincia de Valencia que, además de publicarlo por tal en cada una de las

\footnotetext{
24 ACA, Consejo de Aragón. Leg. 696, doc. 70/2.

25 Ibidem.

26 Ibidem.
} 
comunidades bajo su autoridad, dejasen constancia de ello en los libros de registro conventuales para perpetua memoria de los siglos. También publicarían estas censuras desde sus púlpitos las Iglesias de Gandia, Oliva y Dénia, cuya feligresía bien sabía de las andanzas del antiguo vicario provincial ${ }^{27}$.

La reprobación pública del religioso no fue desaprovechada por sus hermanos de hábito de la facción contraria. En este sentido, solicitaron al definitorio que, habiendo vacado el voto de padre inmediato, por la apostasía del padre Vitoria, y debiéndose proveer según lo que acerca de este punto disponía el papa Urbano VIII, se subrogase en su lugar al padre Juan Rodríguez, ex-ministro provincial de Valencia, como así se ejecutó el 22 de enero en medio de los gritos y abucheos de los frailes afines a fray Jaime Vitoria. El asunto fue denunciado por el propio interesado al auditor de la Cámara Apostólica, al que expuso cómo

en su Provincia se estaba fraguando injustamente un atentado contra su honor, queriendo por ausencia suya substituir otro sugeto en el lugar de padre inmediato que legítimamente poseía, con la prerrogativa de tener voto en capítulo y demás juntas difinitoriales; que no sabía con qué derecho ni razón podrían atreverse a ello, quando expresamente estaba prohibido ${ }^{28}$.

La sentencia hecha pública el 16 de noviembre de 1697 dio la razón al padre Vitoria, restituyéndosele en la plaza reclamada para consternación del comisario general. Fray Antonio Folch de Cardona suspendió entonces el definitorio provincial previsto para comienzos del nuevo año. Acto seguido, impugnó ante el nuncio don José Archinto el monitorio despachado por la Cámara Apostólica, un documento subrepticio, en su opinión, basado en falsas informaciones que confundían la ausencia legítima de la Provincia con una justa apostasía penada con toda suerte de censuras, " una de las quales es privación de entrar en difinitorio por algunos años..."29

Así lo reconocería el nuncio con su declaración del 9 de abril de 1698. Declaración que fray Antonio llevaría consigo a Valencia para inaugurar la congregación reunida en el convento de San Francisco el día 27. Estupor el del comisario general cuando, una vez presentada la cédula, el padre Juan Bautista Todo, ministro provincial, se negó a dar lugar a nadie en aquel definitorio a costa de los derechos de fray Jaime Vitoria, conforme había dispuesto la Cámara Apostólica. De los definidores allí presentes, sólo respaldaron esta negativa los padres Gelasio Zarco y Andrés Morató. Por

27 Manifiesto de los justos procedimientos hechos por el reverendissimo padre fray Antonio Folch de Cardona, commissario general de toda la orden de nuestro padre seráfico san Francisco y de las Indias, en la causa de la apostasía del padre fray Jaime Vitoria. Descríbense los supuesos y fingidos motivos de gravamen injusto con que ha querido notar las más justas y benignas operaciones y se manifiestan las apariencias engañosas de los libelos que se han esparcido, s.1., s.a., s.p., en ACA, Consejo de Aragón. Leg. 696, s. d. La versión latina de este impreso en Biblioteca Universitaria de Valencia (BUV), Ms. 706 (4), Manifestatio ostensio, et apología integerrimae aequitatis, et synceritatis, qua reverendissimus pater frater Antonius Folch de Cardona, commissarius generalis totius patris nostri seraphici sancti Francisci religionis, Indiarum, se gessit in causa apostasiae patris fratris Iacobi Vitoria. Aperiuntur ficta, simulataque iniusti gravaminis motiva, quibus aequiores, benignioresque reverendissimi patris operationes aliqui notare conati sunt; simulque deteguntur fallaces species, sive apparientiae libellorum quin in vulgus prodierunt, s.1., s. a.

28 Martínez Colomer, op. cit. (nota 6), p. 430.

29 Ibidem, p. 435. 
su parte, fray Crisóstomo Bernabeu y fray José Olucha se pusieron de lado del padre Folch de Cardona, quien empleó todos los recursos a su alcance para imponer a fray Juan Rodríguez en sustitución del padre Vitoria. Acompañarían a éste en su exclusión del definitorio fray Félix Francés y fray Fernando López, relevados por un hombre de confianza del comisario general, el padre Andrés Ibáñez, lector jubilado y predicador real $^{30}$.

Ni el antiguo vicario provincial ni sus partidarios iban a darse tan pronto por vencidos. En verano salió a la luz una supuesta sentencia absolutoria del primero rubricada por el ministro general franciscano, fray Matteo de Sancto Stefano. Andaba avalado el susodicho documento -en su doble versión, castellana y latina- por un consulto atribuido a seis religiosos "de la primer literatura y virtud del orden seráfico" ${ }^{31}$. Antes de concluir el año ejemplares impresos de ambos papeles inundaban ya, literalmente, la ciudad de Valencia y otras muchas localidades del antiguo reino proclamando la inocencia del padre Vitoria, confirmada, distribuida y registrada en los libros conventuales de los principales establecimientos religiosos de la Provincia por orden de fray Juan Bautista Todo ${ }^{32}$. Desde entonces el mismo ministro provincial utilizaría el púlpito, en palabras de sus opositores, para "canonizar los passos de Vitoria y fuertemente reprehender los que davan sus superiores a fin de corregirle..." ${ }^{33}$.

\section{La guerra de los libelos}

El 19 de enero de 1699 fray Pedro Manuel de Aguilón, en representación del comisario general de los franciscanos, compadecía ante el nuncio apostólico para denunciar los acontecimientos ocurridos en Valencia durante las últimas semanas

se han fixado en todas las partes públicas, puertas de yglessias seculares y rregulares, unos cedulones con incerción de una sentencia que, en virtud de un consulto que refiere haver dado seys padres graves de dicha orden, profirió el ministro general de ella a favor del padre Jayme Victoria, declarando en ella su inocencia y que no cometió delito ni incurrió en excomunión alguna, por haver salido in consueto omni perlato del convento donde le tenía asignado la obediencia y haver hido a Roma a la presencia del dicho ministro general ${ }^{34}$.

La aparición de estos libelos había supuesto un motivo más de discordia entre los religiosos, en torno a los cuales se habían alineado los vecinos, tanto que

30 BUV, Ms. 706 (3), Valentina congregationis, seu capituli intermedii almae Provinciae Valentiae fratrum minorum Sancti Francisci de observantia, celebratae die 27 aprilis 1698 in regali Sancti Francisci conventu eiusdem civitatis. Praeside reverendissimo patre Antonio Folch de Cardona, commissario generali, etcétera.

31 Lo eran los padres Miguel Ángel de Candia, Juan Bautista Atina, Juan Jacobo de Roma, Antonio de Pannono, Lorenzo de San Lorenzo y Tomás Granello, todos ellos con importantes responsabilidades, pasadas o presentes, en las filas de san Francisco. Ejemplares de ambos libelos, tanto en latín como en castellano, se hallan contenidos en los impresos citados en la nota 23.

32 Martínez Colomer, op. cit. (nota 6), p. 438.

33 ACA, Consejo de Aragón, Leg. 696, doc. 70/66.

34 Ibidem, s. d. 
entre los seglares ha habido y están pasando muchas disenciones y diferentes riñas, causadas de que unos pretenden quitar, y otros impidir que se quiten, dichos cedulones, llegando esto al estrecho de ussar de las armas con notorio riesgo de las vidas, pasando, assimesmo, esto entre los religiosos, aplaudiendo unos al padre Victoria y otros opponiéndose con menos peligro de escándalos, menosprecio del santo ábito, gran diminución de la observancia religiosa y una total inedificación de los seglares ${ }^{35}$.

Y como muestra del revuelo general, un ejemplo, protagonizado junto al portal de San Vicente por los padres Pedro Masquefa y Diego García, del valentino convento de San Francisco

habiendo visto dos sentencias, quitó fray Pedro la una por sus manos y el dicho padre Diego la otra. Y que a este tiempo salieron a defender y a impedir la desfixación de dichas sentencias Thomás Mira, errero de officio, el qual Mira amenazó a fray Pedro diciéndole que, si no fuera religioso y sacerdote, vengaría en él dicho atrevimiento ${ }^{36}$.

O el todavía peor lance acaecido a plena luz del día en Oliva,

por querer un religioso, llamado el padre fray Francisco Gozalves, predicador conventual del convento de dicha villa, arrancar uno de los papelones que se habían fixado, sacó un puñal contra dicho religioso, o contra el hombre que le acompañava, un beneficiado de dicha iglesia de Oliva, llamado mosén Antonio Mañans, con grave escándalo... Y que el mismo predicador, queriendo quitar otro papelón de los que estaban fixados en dicha villa, se le oppuso y salió a defenderle un hombre llamado Martínez, el Infant, labrador de dicha villa, y le dixo al dicho predicador diferentes injurias, y que le haría poner en un palmo de cadena ${ }^{37}$.

Visto lo visto, a través de su representante legal, fray Antonio Folch de Cardona sometía el caso a la nunciatura, a la que reclamaba el urgente envío a Valencia de un comisario apostólico con amplios poderes para que

averigue todos los escándalos, turbulencias, inquietudes y disenciones que se han causado y están causando en estas publicaciones, inquiriendo y averiguando quiénes han sido y son los actores y factores de ellos que han causado y causan tales escándalos y disturbios; y de orden de quién se han impresso dichos papelones; y quién lo ha executado; y con qué auctoridad, no aviendo asta aora tenido noticia de semejante noticia y consulto el commisario general por otro medio que los referidos escándalos, y que se le dé facultad para que pueda proceder a impedir y asosegar los dichos escándalos, peligros de inquietudes y discenciones por los medios y providencias que más bien visto le fueren, procediendo para ello contra todas y qualesquiera personas de qualquier estado y calidad que sean, y que la información que hiziere, providencia que tomare y papeles que recogiere, los remita todos originales a vuestra illustríssima ${ }^{38}$.

\footnotetext{
35 Ibidem.

36 Ibidem, doc. 70/51.

37 Ibidem.

38 Ibidem, s. d.
} 
La solicitud del comisario general fue admitida a trámite por el nuncio. Recaería el encargo en el obispo de Segorbe, don Antonio Ferrer y Milán ${ }^{39}$, cuyas múltiples ocupaciones le obligaron a subdelegar en la persona del doctor Blas Llosá, canónigo magistral de la seo segorbina.

Para entonces, el Consejo de Aragón había informado ya a Carlos II de la aparición de los libelos franciscanos ${ }^{40}$. El soberano escribió al ministro general de san Francisco, fray Matteo de Sancto Stefano, para expresarle su inquietud por "las diferencias que hay entre vuestros religiosos del convento de San Francisco de mi ciudad de Valencia". No eran una novedad las cuitas internas de los frailes, reconocía, si bien su contagio al pueblo empezaba a preocuparle seriamente "porque puede prorrumpir en perturbación de la quietud pública". En sus manos, pues, estaba que "aquellos religiosos se moderen en semejantes demostraciones, ciñendo sus controversias a los límites de los claustros". De lo contrario, advertía el monarca, sería la corona la que aplicara los correctivos contra tales individuos indignos del hábito que vestían ${ }^{41}$.

Por el momento, en su primer informe acerca de lo acontecido, el virrey de Valencia don Alonso Pérez de Guzmán, caballero y gran cruz de la orden de san Juan de Jerusalén ${ }^{42}$, restó importancia al asunto de los cedulones, protagonizado esencialmente por eclesiásticos, y por tanto ajeno a su competencia. Según había podido saber el lugarteniente general del reino, tras la edición de estos papeles no se hallaba sino el canónigo Vicente Vitoria, que auxiliado por algunos franciscanos de la parcialidad de su hermano habría recurrido a la pequeña imprenta que el mercedario fray Juan Bautista Aguilar ${ }^{43}$ disponía en el convento de Nuestra Señora del Remedio. De los

39 Doctor en ambos Derechos, catedrático pavorde del Estudi General y obispo auxiliar de Valencia, desde 1686, el oratoriano Ferrer y Milán había sido designado para la mitra segorbina el 19 de diciembre de 1692. En aquella diócesis ejercería el ministerio episcopal hasta su muerte, que sobrevino en octubre de 1707. AgUILAR, F: Noticias de Segorbe y su obispado, Segorbe, F. Romaní y Sucy, 1890, vol. I, pp. 461-468; Llorens Raga, P.: Episcopologio de la diócesis de Segorbe-Castellón, Madrid, CSIC, 1973, vol. I, pp. 399-402; y GuITARTE IzQuierdo, V.: Obispos auxiliares en la historia del arzobispado de Valencia, Castellón, Ayuntamiento de Castellón, 1985, p. 60.

40 ACA, Consejo de Aragón, Leg. 695, doc. 33/2.

41 Ibidem, doc. 33/5.

42 Mateu Ibars, J.: Los virreyes de Valencia. Fuentes para su estudio, Valencia, Ayuntamiento de Valencia, 1963, pp. 222-224.

43 Este religioso valenciano había profesado en la familia trinitaria calzada el 2 de febrero de 1655 . Desde entonces, había pasado por los conventos que la orden poseía en Lliria y Valencia, del que llegó a ser regente de estudios. Ocupó otras responsabilidades entre los suyos, como visitador de la Provincia de Aragón y presidente de algunos capítulos provinciales. Maestro en Sagrada Teología, " floreció mucho en la poesía y letras humanas, sin dexar de hacer sus progressos en otras ciencias y facultades mayores". Avalan su pasión literaria las siguientes obras, impresas mayoritariamente en las prensas del convento del Remedio: Varias hermosas flores del Parnaso, que en quatro floridos vistosos quadros plantaron junto a su cristalina fuente diferentes poetas ilustres de España, Valencia, 1680; Theatro de los Dioses de la gentilidad, Valencia, 1680; Sermones del ilustríssimo y reverendissimo señor don fray Martín Iváñez de Villanueva, religioso de la orden de la Santíssima Trinidad, arzobispo de Rijoles, Valencia, 1697; Fabio instruido de Lelio a Lauro, Valencia, 1700; Traducción del idioma toscano en español del Epitome del Reyno de Italia baxo el yugo de los bárbaros, que escribió el conde Manuel Thesauro, Valencia, 1701; y El silencio misteriosamente hablador, en la Vida de san Bruno, que escribió en Toscano el reverendíssimo padre don Buenaventura a Tondi, monge olivetano. Traducida en español con exornación de noticias y addición de algunos capítulos, Valencia, 1702. Murió en 1714. XIMENo, op. cit. (nota 9), vol. II, pp. 169-170. 
tres seglares que trabajaban en aquellas prensas, uno de ellos había sido encarcelado, no así los otros dos, debido a su mocedad ${ }^{44}$.

Tales extremos fueron confirmados por la investigación que el subdelegado apostólico inició a comienzos de febrero de 1699. En el domicilio que su familia poseía en la capital valentina -donde residía sus hermanos Juan Bautista y José, este último franciscano descalzo- estableció Blas Llosá su cuartel general, por el que desfilaron decenas de testigos, seglares y eclesiásticos, regulares y seculares. Según los testimonios de éstos, Vicente Vitoria, asistido por el partido seráfico opuesto al comisario general, parecía ser el principal culpable de todo. Antes incluso de que los libelos fueran conocidos, había hecho lo imposible por rehabilitar el honor del antiguo vicario provincial. En este sentido, coaccionó a los primeros informantes que habían depuesto ante el secretario de fray Antonio Folch de Cardona sobre las relajadas costumbres de su hermano, amenazándoles de muerte en caso de no retractarse notarialmente de sus declaraciones ${ }^{45}$.

Vendría luego la hipotética sentencia absolutoria del padre Vitoria, que el canónigo puso en circulación, manuscrita y en latín, con la ayuda de fray Vicente Solves, del convento seráfico de la Corona. Traducida al castellano por el notario Francisco Barco, Vicente Vitoria encargó la impresión de dos mil ejemplares del documento -en su doble versión- a fray Juan Bautista Aguilar y sus jóvenes colaboradores, Manuel Solano, Antonio Montoro y Victoriano Casanova. En el convento de Nuestra Señora de Jesús se habían preparado los pliegos para su distribución por parte de los padres franciscanos Victoriano Monter, José Guerola, Vicente Mazó, Cristóbal Marí y Juan Domingo. Del reparto por cenobios, parroquias y casas particulares de la capital y el reino entero se ocuparon, junto al mismo canónigo, los religiosos de la Corona fray Pedro Rujart y fray Francisco Llopis. Operaciones rematadas por otros tantos frailes de la misma orden, como los padres Pascual Semper, sacristán del convento femenino de la Santísima Trinidad, o Bautista Bernat y Salvador Cobos, ambos de San Francisco, con el pegado masivo de estos impresos por todas partes ${ }^{46}$.

El primero de todos estos imputados en purgar sus culpas, cómo no, sería Vicente Vitoria. Detenido y encarcelado preventivamente, fue puesto a disposición de la jurisdicción eclesiástica por parte del subdelegado apostólico. En ausencia del entonces arzobispo de Valencia, el inquisidor general fray Juan Tomás de Rocabertí, se ocuparía de instruir la correspondiente causa criminal su vicario general don José García de Azor ${ }^{47}$.

Con todo, la labor del doctor Blas Llosá fue cuestionada por la Audiencia de Valencia, que le acusó de no haber presentado oficialmente su comisión antes de ejercerla, como era preceptivo en estos casos. De nada sirvieron a la jurisdicción real registros

\footnotetext{
44 ACA, Consejo de Aragón, Leg. 695, doc. 33/3.

45 Por ejemplo, al dorador Bernardo Polo, al que aseguró " le era muy fácil el hazer darle una escopetada valiéndose de los conocidos que tiene en La Marina, a quienes no conocen en Valencia". ACA, Consejo de Aragón, Leg. 696, docs. 70-74.

46 Ibidem, docs. 70/47-70/51.

47 El doctor García de Azor, arcediano de Alpuente, doctor en Leyes y Cánones y pavorde, se dedicaba desde octubre de 1695 a las tareas pastorales inherentes a su oficio de vicario general, gobernador y provisor del arzobispado, en ausencia del padre Rocabertí. Callado Estela, E.: Por Dios y por el Rey. El Inquisidor general fray Juan Tomás de Rocabertí, Valencia, Alfons el Magnànim, 2007, pp. 378-379.
} 
y apercibimientos para hacerse con el documento original de la delegación, cuyos pormenores acabó conociendo a través de las copias de otros papeles ${ }^{48}$. Fue entonces cuando las dos salas del Tribunal constataron la vulneración que esta comisión suponía para las regalías de la corona. No se trataba únicamente de la ocultación de unas credenciales, sino del alcance de su contenido, al afectar tanto a eclesiásticos, súbditos de la Iglesia, como a seglares, contra quienes nada podía pretender el nuncio sin licencia previa del banco regio, bajo cuya autoridad estaban; menos todavía después de que la justicia real hubiera iniciado su propia investigación saldada con un primer encarcelamiento ${ }^{49}$.

A estos argumentos añadiría el virrey don Alonso Pérez de Guzmán sus críticas a los procedimientos instruidos por el subdelegado apostólico, que

han sido con irregular método y más horrorosos que los de los inquisidores, pues sin llamar a [los testigos] les imponía por primera la pena de excomunión para que acudiessen a su casa, y esto se executava a horas desusadas y tan intempestivas ${ }^{50}$.

Una razón más, en fin, para que la nunciatura suspendiera la comisión en curso y la rectificara, sentenciaba el noble, de modo que quedara limitada a la esfera que estrictamente le correspondía, y por tanto reintegradas a la corona las regalías perjudicadas.

No lo veía ni mucho menos así don José Archinto, que defendió ante el monarca al doctor Llosá sosteniendo la legalidad de sus acciones, sobre las cuales aseguraba haberse iniciado con el conocimiento y visto bueno de la lugartenencia general del reino ${ }^{51}$. Sin embargo, y para satisfacer las demandas de la corona, se revocarían y anularían en breve todos los expedientes hasta entonces instruidos contra seglares mientras la delegación se diluía ${ }^{52}$.

\section{Delitos y faltas}

El Consejo de Aragón abordó la situación creada en Valencia por la publicidad de las pendencias franciscanas, la actuación del virrey y los excesos de la comisión apostólica. La gestión de don Alonso Pérez de Guzmán no había estado a la altura de las circunstancias. Primero, por desdeñar los problemas internos de la orden de san Francisco, que jamás deberían haber trascendido de sus conventos. Después, ya públicos y notorios, había seguido restándoles importancia, inhibiéndose prácticamente de ellos, como asuntos de eclesiásticos que decía eran, mientras se ocupaba solamente, y de manera muy liviana, del puñado de seglares implicados. Sin embargo, el noble

\footnotetext{
48 ACA, Consejo de Aragón, Leg. 696, docs. 70 / 52 - 70 / 59.

49 Ibidem, docs. 70/35-70/40.

50 Ibidem.

51 Ibidem, doc. 70/34.

52 ACA, Consejo de Aragón, Leg. 695, docs. 33/14-33/17.
} 
no debía ignorar, a vista de aquella Real Audiencia, que el cuerpo político de la República se compone de los que la havitan, sin diferençia de estados. Y que, por esta razón, los eclesiásticos y regulares, como parte de este cuerpo, están sujetos a la cabeza, que es el príncipe, y son súbditos suios, con obligaçión de obedezerle en lo que tocase al beneficio unibersal de todas las partes que le forman, sin que la residencia de éstos se considere más que como una cosa temporal, y assí les puede privar de ella con justas y urgentes causas, echándolos de sus tierras y multándolos, como el casso lo pidiese, si ocasionaren escándalos o se temiese que pueden ser en grabe manera perjudiciales al estado público, obligándolos por estos medios a que vivan reformados y atentos a no exceder de su estado y obligaciones ${ }^{53}$.

De esta potestad llamada económica y gozada por cualquier soberano de la cristiandad sobre los eclesiásticos - que la corona y sus ministros enarbolaban últimamente con mayor frecuencia, en su acoso y derribo a la jurisdicción privilegiada de la Iglesia ${ }^{54}$ - se habían valido de forma delegada los predecesores de don Alonso en la lugartenencia general valentina desde tiempo inmemorial para evitar graves males a la Monarquía, "apartando las personas eclesiásticas y regulares que pudieran ocasionarlos". Era lo que debía hacer en este caso el actual virrey sin temblarle el pulso. Por supuesto con el canónigo Vicente Vitoria, al que desterraría hasta nuevo aviso a veinte leguas del reino de Valencia, con mandato expreso de no pasar a la corte. También con el padre trinitario Juan Bautista Aguilar, cuyo traslado a otro convento fuera de la capital, donde no tuviera nunca más acceso a una imprenta, ordenaría a sus superiores. Sin olvidarse del ministro provincial de san Francisco, responsable último de los altercados sucedidos desde el último definitorio

Fray Juan Baptista Todo ha sido el que con más excesso ha mostrado su passión en este caso, esparciendo las sentençias y embiándolas a los combentos de su Provinçia para que se leiessen en la comunidad, inquietando por este medio inussitado e irregular a sus súbditos. Y por haberse aplicado en el púlpito, con proposiçiones que pudieran conturbar a los oyentes e induçirlos a sediçiones..., pareze conveniente que se le saque de la Provincia, por medio de su superior, y que éste embíe visitador que sea de la satisfacçión y entereza que se requiere para que se reduzca la observançia a su debido estado. Y que en el ínterin que no se concluiese la visita, no se le permita al provincial entrar en su Provincia, porque no embaraze con su solicitud los efectos y fines de ella ${ }^{55}$.

Se recomendaba, por último, que don Alonso Pérez de Guzmán procediera criminalmente y de manera ejemplar contra los seglares implicados en los lances franciscanos. Entre ellos, quienes de algún modo habían colaborado en la impresión, distribución o pegado de los hipotéticos documentos absolutorios de fray Jaime Vitoria, independientemente de su edad, estado y condición.

53 Ibidem, docs. 33/6-33/7.

54 Véanse al respecto los ya clásicos trabajos de MARqués, J. M.: "Entre Madrid y Roma. La nunciatura de Madrid en 1675", Anthologica Annua, 26-27 (1979-1980), pp. 407- 553, y "La Santa Sede y la España de Carlos II. La negociación del nuncio Millini. 1675-1685”, Anthologica Annua, 28-29 (1981-1982), pp. 259262. Para el caso valenciano, CAllado Estela, E.: Inmunidad eclesiástica y delincuencia en el siglo XVII. Los arzobispos de Valencia y la pacificación del reino (1612-1699), Valencia, Biblioteca Valenciana, 2003.

55 ACA, Consejo de Aragón, Leg. 695, docs. 33/6-33/7. 
Carlos II aprobó el dictamen del Consejo de Aragón el 24 de febrero de 1699. En esa fecha escribió un correo urgente al virrey de Valencia participándole sus órdenes al respecto del canónigo Vitoria, los padres Aguilar y Todo y demás involucrados en la trama de los libelos ${ }^{56}$. Algo más tarde dirigía una misiva al ministro general de san Francisco para solicitar su colaboración con fray Antonio Folch de Cardona en el apaciguamiento de la Provincia franciscana valentina, a la que no debía consentir por ahora que regresara su antiguo vicario ${ }^{57}$.

En la estafeta ordinaria a la corte de comienzos de marzo, don Alonso Pérez de Guzmán dio cuenta de las últimas gestiones operadas en este asunto ${ }^{58}$. Vicente Vitoria continuaba preso en las cárceles episcopales, de donde no había podido sacarlo para su destierro debido a las reticencias del vicario general de la diócesis, en cuyo tribunal se instruía ya una causa penal contra el canónigo, lo que en opinión de la Real Audiencia anulaba la concurrencia de la potestad económica. Podría excarcelársele por la fuerza, aunque resultaría "muy aventurado lo ruidoso de esta demonstración". Sobre fray Juan Bautista Aguilar y fray Juan Bautista se preguntaba el noble si, sus superiores no lo hicieran, "ha de executarse el sacarles con estrépito o sólo haziéndoles notoria la parte que les toca de esta real orden para que sea la más decorosa esta diligencia". Nada se había practicado tampoco con los seglares sospechosos, "porque los materiales que se juntaron no han parecido bastante para su plena prueba". Se trataba sólo de unos cuantos muchachos, no obstante, arrastrados por las trifulcas franciscanas, que en absoluto suponían una amenaza para la estabilidad del reino de Valencia. Mucho más daño que cuatro frailes había provocado la presencia del comisario apostólico subdelegado del nuncio, al que no perdonaba el virrey su actuación

las turbaciones han comenzado desde que el canónigo Llosá vino a cunplir este encargo, por haver hecho elección de possada en la cassa de su hermano, y con este motivo y de haver citado al provincial de esta Provincia para que exibiesse la que llaman sentencia original que, con patente suya, havía corrido por los combentos de ella $\mathrm{y}$ acudido diferentes procuradores y agentes a los emplazamientos, se pudieron recelar escándalos por salir a las audiencias fray Joseph Llosá, sugeto de natural ardiente y poco a propósito para la indiferencia con que deven portarse los juezes, y en algún el doctor Juan Bautista Llosá, que no tiene empleo en la comisión ${ }^{59}$.

Antes de que estas informaciones llegaran a su destinatario, el general de la orden de la Trinidad habría cursado ya la orden para que fray Juan Bautista Aguilar, conforme a la regia voluntad, abandonara Valencia y se afincara en un convento de Xàtiva, adonde llegaría en breve ${ }^{60}$. Mayores complicaciones, por el contrario, acarrearon al comisario general de los franciscanos el destierro del padre Todo, como cabía esperar.

Fray Antonio Folch de Cardona había dispuesto que el religioso, so pena de excomunión mayor latae sententiae ipso facto incurrenda, se personara de inmediato

\footnotetext{
56 ACA, Consejo de Aragón, Leg. 696, doc. 70/11.

57 Ibidem, s. d.

58 Ibidem, docs. 70/12-70/15.

59 Ibidem, docs. 70/35-70/40.

60 Ibidem, doc. 70/10.
} 
ante el ministro provincial de Aragón, quien le indicaría el establecimiento concreto para su encierro en aquella demarcación ${ }^{61}$. Debía entregar previamente los sellos y registros provinciales a fray Crisóstomo Bernabeu, lector jubilado de Teología y protegido del comisario general, que durante su ausencia se ocuparía del gobierno de la Provincia franciscana de Valencia, según letras despachadas en Madrid por el propio padre Folch de Cardona con el propósito de reconciliar a sus frailes

Le damos toda la autoridad quanta de derecho se requiere y tienen los Ministros Provinciales para que, assí en quanto a los religiosos, como también a las religiosas, govierne la dicha Provincia y la rija por todo el tiempo que dicho muy reverendo padre Provincial estuviere ausente; haga y execute quanto dicho muy reverendo padre provincial executaría y executar pudiera por razón de su oficio; y por quanto la visita de dicha Provincia no se ha concluido hasta ahora, mandamos a vuestra paternidad que luego la prosiga y concluya, portándose en ella con gran despasión o indiferencia, atendiendo sólo a Dios y a hacer su causa y de la religión, procurando corregir y castigar los delitos sin el más mínimo movimiento de venganza, solicitando por todos los medios prudenciales posibles pacificar los ánimos de todos los religiosos y religiosas, que es el primer móvil que ha de gobernar todas las operaciones de vuestra paterni$\operatorname{dad}^{62}$.

Una repentina enfermedad, sin embargo, pospondría sine die la marcha de fray Juan Bautista Todo $^{63}$. Hasta el convento valentino de la Corona, donde andaba encamado entre purgas y sangrías, acudió el emisario del comisario general para ejecutar la orden de destierro. Nada pudo hacer frente a la vehemente oposición de los religiosos más afines al padre Todo, quienes los despacharon de allí con amenazas. Varios de estos frailes se personaban a continuación ante el virrey con una certificatoria médica sobre el grave estado de salud del ministro provincial, advirtiéndole "se tumultuaría la Provincia si se executava el apartamiento del provincial" y se entronizaba en su lugar a fray Crisóstomo Bernabeu. Semejante posibilidad era desmentida poco después por otros tantos religiosos de la facción contraria, que avalaron la idoneidad del hombre escogido para guiarles en aquel ínterin, "sugeto el más apartado de pretención, más benigno y amigo de la paz que se ha conocido"64.

La toma de partido de los jurados de Valencia por uno de estos dos bandos no hizo sino echar más leña al fuego. Para los munícipes, el resultado del último capítulo provincial franciscano, reunido en Alicante el año 1696, jamás había sido aceptado por los émulos del padre Juan Bautista Todo,

61 ACA, Consejo de Aragón, Leg. 695, doc. 70/25.

62 Cit. Martínez Colomer, op. cit. (nota 6), p. 441.

63 A tenor del informe médico oficial, "dicho muy reverendo padre provincial padece actualmente una distilación grave que le obliga, casi de ordinario, a vehemente tos. Assimesmo, un tumor en el emunctorio drecho de la cavidad vital hecho de materias frías y gruesas. Un dolor articular en las rodillas, que le impiden el movimiento. Para reparar los quales accidentes, previniendo la medicina la curación de aquéllos, como la precaución de otros que se pueden tener y se rezelan, se le han hecho tres sangrías y en todas ellas se ha observado en la sangre una mala disposición. Y assimesmo, se le está preparando con jarabes". ACA, Consejo de Aragón, Leg. 696, doc. 70/23.

64 ACA, Consejo de Aragón, Leg. 695, doc. 70/24. 
religioso de inocencia cierta, virtud acreditada con el exemplo de inculpable vida, que padece inosente la mortificación de haverle mandado salir deste reyno, que huviera executado siegamente y con resignación christiana y religiosa si una grave enfermedad que padese no se lo dificultara ${ }^{65}$.

Como él, tanto o más habían sufrido los incondicionales del ministro provincial, "los más acreditados en la observancia de su instituto y los más nesesarios para el provecho universal de los vecinos"

De estos últimos sucesos informaría a la corona un preocupado don Alonso Pérez de Guzmán. Por primera vez desde la publicación del presunto consulto y sentencia absolutoria de fray Jaime Vitoria, el virrey reconoció la posibilidad de que este asunto pudiera acabar escapando a su control, pues "estaban turbados los ánimos de muchos religiosos, y por las disensiones en que se hallan podía recelarse algún disturbio que trascendiese afuera". De ahí que, por ahora, hubiera suspendido la salida del padre Todo a la espera de que las aguas se remansaran ${ }^{67}$.

En absoluto agradaron a Carlos II las noticias llegadas desde Valencia. El 8 de marzo de 1699 recriminaba severamente a su lugarteniente general en este reino el incumplimiento de las órdenes expedidas el día 24, muy particularmente las referidas a los destierros del canónigo Vicente Vitoria y del provincial franciscano. En cuanto al primero, no había podido conducirse el noble con mayor tibieza ya que

ha pasado a fundar todo lo que destruye lo más esencial de mis regalías, haciendo disputable o dudossa la potestad de apartar al canónigo Victoria, bien que sea presso del vicario general..., pues ni remotamente se deve dar lugar a esto, porque sería lo proprio que arruynar los santos, justificados y sólidos fundamentos con que Dios me concedió este derecho indisputable en la substancia y sin ser admisible controversia en su práctica ${ }^{68}$.

Y algo similar había hecho en el segundo de los casos, ante la oportuna indisposición de fray Juan Bautista Todo,

porque aunque mi real benignidad quiera permitir la representazión a mis reales órdenes, es quando éssa excluye razones muy fundadas de mi real servicio, pero no quando se viste de aéreos motivos que miran a impedir o tomar tiempo en la execuzión de ellas ${ }^{69}$.

Ambas disposiciones, pues, debían ser ejecutadas sin más evasivas ni demoras, finalizaba el rey su amonestación, velando en todo caso por la salvaguarda de la paz pública.

Precisamente ésta última sería el argumento empleado en su defensa por don Alonso Pérez de Guzmán. El 17 de marzo manifestaba al soberano haber actuado en el

\footnotetext{
65 ACA, Consejo de Aragón, Leg. 696, doc. 70/9.

66 Ibidem.

67 Ibidem, docs. 70/21-70/22.

68 Ibidem, docs. 70/77-70/78.

69 Ibidem.
} 
caso presente " con la más rendida obediencia”. Del ministro provincial, nada había ya que decir. Aún enfermo, acababa de abandonar la ciudad de Valencia por su propia voluntad, con destino a Aragón, sin necesidad de que ninguno de los oficiales reales puestos a disposición de las autoridades franciscanas interviniera en ello ${ }^{70}$. Cuestión diferente era la del hermano de fray Jaime Vitoria. La entrega del susodicho al banco regio todavía no se había producido, pese a lo cual el virrey continuaba desaconsejando cualquier represalia contra la jurisdicción eclesiástica, por justa y merecida que fuera, pues "en lo dilatado y numeroso del estado ecclesiástico se incluyen muchos inquietos que tendrían a gran fortuna, en traje de mérito por su defensa, cometer muchos desahogos y aún insultos". Nada menos recomendable, en fin, que entablar un nuevo contencioso que a nadie beneficiaría. Tampoco otras posibles soluciones, al menos en poder de la lugartenencia general, garantizaban que la situación no terminara desbordándose

no se encuentra medio que no sea conocidamente arriesgado para que el real orden se execute con repugnancia del ordinario; y éste no he de practicarle por mayor servicio de vuestra magestad ni ser testigo de que, por este accidente, se malogre el desvelo con que en todo el tiempo de mi govierno se ha establecido para librarle de las opressiones en que estaba y mantenerle en $\mathrm{paz}^{71}$.

Los peores temores del lugarteniente general se desvanecieron poco después con la conclusión de la causa instruida contra el hermano del padre Vitoria por parte del vicario general de la diócesis ${ }^{72}$. El 20 de marzo se hacía pública la sentencia contra él en virtud de la cual se dispuso que "dins vint-y-quatre hores ixca dels arrabals de la present ciutat y dins huit dies ixca del present regne y a vint llegües de distància de la ralla de aquell y que no entre en la vila de Madrid ni torne al present regne" hasta nueva orden ${ }^{73}$. Antes de finalizar el mes, cumplía ya su destierro en Barcelona el canónigo ${ }^{74}$.

La salida de Vicente Vitoria y fray Juan Bautista Todo no libró de nuevos reproches a don Alonso Pérez de Guzmán. El Consejo de Aragón condenó sin paliativos su inobediencia reiterada a las órdenes reales a partir de vanos pretextos, con el consiguiente perjuicio para regalías de la corona como la potestad económica. Tan culpables o más que él eran los ministros de la Real Audiencia, que le habían asesorado, y el vicario general del arzobispado, por sacar provecho de las circunstancias. Todos merecían una reprimenda acorde a sus faltas, como se recomendó a Carlos II

70 ACA, Consejo de Aragón, Leg. 695, doc. 33/19. El estado de salud del padre Juan Bautista Todo le obligó a detenerse por un tiempo en el convento franciscano de Massamagrell, cuyo guardián fray José de la Olleria certificó que " no podía proseguir su jornada sin manifiesto peligro de su vida". Ibidem, doc. 33/23. Algo mejor, el 2 de abril retomaba el camino hacia su destierro, concretado finalmente en la localidad aragonesa de Alcoriza, adonde llegó el día 11 " muy pálido y descolorido”, según los frailes del lugar. Ibidem, doc. $33 / 24$.

71 Ibidem, docs. 33/14-33/17.

72 Ibidem, doc. 33/20.

73 Ibidem, doc. 33/21.

74 Lo confirma el acta notarial levantada el 1 de abril en la Ciudad Condal, con los testimonios del franciscano fray Bautista Barnat, de la Provincia de Valencia, y otros dos seglares. ACA, Consejo de Aragón, Leg. 696, doc. 70/99. 
en la consulta fechada el 3 de abril de 1699. En cuanto al lugarteniente general, "será muy propio de la justificación de vuestra magestad el reprenderle, advirtiéndole el que escuse el escribir con semejantes vozes y juntamente por la omisión tan culpable como el no executar las órdenes de vuestra magestad". Por su parte, a los miembros de la Audiencia "mande darles muy severa reprensión, advirtiéndoles se trata de la aberigüación de los más culpados para que experimenten castigo correspondiente al delicto". Finalmente, el doctor José García de Azor debía ser apercibido para que, como máximo responsable de la jurisdicción eclesiástica en ausencia del ordinario, "no impida a vuestra magestad el uso de la regalía y potestad económica con supuestos tan déviles como han intervenido en esta materia"75.

El monarca tomó la palabra al Consejo de Aragón en la reprensión de vicario general, Real Audiencia y virrey ${ }^{76}$. Particularmente duro se mostraría con este último, a quien escribió lo siguiente

por lo mucho que conviene que, en adelante, se mantenga indemne [la potestad económica], he resuelto... advertiros quán gravemente havéis faltado a vuestra obligación en lo que os tocaría para su manutención en no haver dado cumplimiento a mis reales órdenes sin embargo de la precisitud con que se os ordenava su execución, difiriéndola en conocido riesgo de la paz y quietud pública de esse reyno..., pasando a límites en que os debía contener el respecto y llegando a términos de indisculpable excesso, el qual hera digno de muy severa demostración a no mediar mi real benignidad y la segura confiança de que esta advertencia os ha de servir de tal emienda por lo venidero y de tal regla como se deven ovedecer mis reales órdenes y mandatos ${ }^{77}$.

Don Alonso Pérez de Guzmán apenas tendría ocasión de mostrar su enmienda, al no ser renovado al frente de la lugartenencia general del reino, por deseo del rey, durante un nuevo trienio ${ }^{78}$.

\section{Pax Huic Domui}

Zanjado el asunto de la contravención a sus reales órdenes, Carlos II se apresuró a exigir al ministro general de los franciscanos una mayor implicación en la pacificación de la Provincia de Valencia ${ }^{79}$. En su descargo, fray Matteo de Sancto Stefano aprobó la gestión del comisario general, cuya autoridad "debo asegurar a vuestra ma-

\footnotetext{
75 Ibidem, doc. 70/62. A la consulta en cuestión se añadirían los votos particulares de tres miembros del Consejo de Aragón. Don Juan de la Torre eximió de cualquier responsabilidad tanto al virrey como a la Real Audiencia, cuya moderación alabó. En idénticos términos se expresó don Juan Luis López, para quien tampoco al vicario general podía imputársele falta alguna. Por el contrario, el marqués de Castelnovo cargó las tintas sobre los ministros de la Audiencia, para quienes reclamó un castigo ejemplar, hasta "supender tres o quatro de los que, tras judicialmente, se entiende han sido los más culpados y sacarles de Valencia”. Ibidem, doc. $70 / 2$.

76 ACA, Consejo de Aragón, Leg. 695, doc. 33/1.

77 Ibidem, doc. 33/41.

78 García Martínez, S.: Valencia bajo Carlos II. Bandolerismo, reivindicaciones agrarias y servicios a la monarquía, Valencia, 1991, Ayuntamiento de Villena, p. 262.

79 ACA, Consejo de Aragón, Leg. 695, doc. 33 / 33.
} 
gestad que todos los padres de esta familia, y yo sobre todos, estimamos muchíssimo, tanto por su grado que tiene como por su virtud, letras y zelo grande en su gobierno". No volvería el padre Jaime Vitoria a importunarle, por cuanto permanecería en Roma hasta que la corona dispusiese... ${ }^{80}$

Aparte de buenas palabras, poco más había hecho el ministro general para contener las maniobras orquestadas por el antiguo vicario provincial de Aragón contra fray Antonio Folch de Cardona. Ni él ni nadie habían impedido al padre Vitoria representar al papa Inocencio XII el malestar generado entre los frailes valencianos por el comisario general desde el último definitorio,

y que para serenar estas agitaciones y otras muchas que, probablemente, habían de sobrevenir en el capítulo próximo, el mejor expediente era que su santidad subsanase la dicha congregación, reparando los daños que en ella se habían ocasionado y distribuyendo después los primeros empleos de la Provincia en los sujetos más dignos ${ }^{81}$.

Lo cierto y verdad es que la posibilidad apuntada terminaría imponiéndose entre las soluciones con mayor garantía de éxito para la vuelta a la normalidad de esta Provincia franciscana ${ }^{82}$. No resulta extraño, pues, que la corona diera instrucciones a sus agentes en la curia romana para obtener una declaración pontificia en tal sentido, parece que con el compromiso previo de acatarla por parte del padre Folch de Cardona, rendido a la evidencia. El breve en cuestión llegó a Madrid con la primavera de 1699, sin que el comisario general opusiera la menor resistencia, según dejó escrito porque

deseamos con vivas ansias que las largas, quanto molestas dependencias y litigios de dicha nuestra Provincia de Valencia, se concluyan con amigable composición y que se establezca en ella la universal paz tan necesaria para serenar los ánimos que tan fatigados se hallan de tan diuturna inquietud ${ }^{83}$.

Ahora bien, fray Antonio declinó personarse en Valencia para su promulgación. Aludiendo a otros compromisos, delegaría el asunto en el padre Mateo Bayuelo, lector jubilado, ex-custodio de la Provincia de Cartagena y guardián del convento de San Francisco de Murcia, con letras expedidas el 6 de octubre. Doce días después el emisario del comisario general comunicaba a los religiosos valencianos el tenor del último documento pontificio, en virtud del cual, además de quedar rehabilitados como definidores fray Félix Francés y fray Fernando López, se conocerían los nombres de las nuevas autoridades que regirían los destinos de la Provincia hasta la nueva convocatoria capitular. En concreto

el reverendo padre fray Bernardo Joseph Pellizer de Jesús María, comisario general de Tierra Santa, en la corte romana, por ministro provincial; el padre fray Vicente Pérez, lector jubilado, ex-definidor y guardián de San Francisco de Valencia, por custodio; los reverendos padres fray Juan Rodríguez y fray Jaime Victoria, ex-Provinciales,

\footnotetext{
80 Ibidem, doc. 33/36.

81 Martínez Colomer, op. cit. (nota 6), p. 445.

82 ACA, Consejo de Aragón. Leg. 695, doc. 33 / 27.

83 Cit. Martínez Colomer, op. cit. (nota 6), p. 446.
} 
por difinidores de la observancia, y por la recolección, al padre fray Miguel Arrufat, lector de Teología, y guardián de[1 convento de] la Corona de Valencia ${ }^{84}$.

Nadie contaba, sin embargo, con la ausencia del padre Pellicer, en Roma para participar en el capítulo general de la orden. De ahí que, hasta su vuelta, fray Gaspar Cerdá se ocupara del gobierno provincial en calidad de comisario. La interinidad del susodicho fue el último clavo ardiendo al que aferrarse un reducido grupo de frailes que cuestionaron su autoridad para intervenir en las elecciones de guardianes conventuales y otros oficios de la Provincia. El padre Folch Cardona hubo de hacer valer su ascendencia sobre estos religiosos para que depusieran toda resistencia. En este sentido, dirigiría una circular a la Provincia ratificando la legitimidad de fray Gaspar para cualesquiera asuntos relacionados con el regimiento de la orden seráfica en el levante peninsular hasta que el nuevo ministro provincial regresara, en junio de $1700^{85}$.

$* * *$

Los días de fray Antonio Folch de Cardona como comisario general de la familia ultramontana estaban contados. Muy posiblemente la necesidad de pasar página para consolidar la paz entre los franciscanos estuviera detrás de su promoción al episcopa$\mathrm{do}^{86}$. Con ello, la corona daría una salida airosa al religioso, protegido del Almirante de Castilla, don Juan Tomás Enríquez de Cabrera y Toledo, y de la propia reina doña Mariana de Neoburgo. Pero no como arzobispo de Caller, según había previsto en un principio, sino, paradójicamente, como titular de la mitra valentina, de la que tomó posesión casi al mismo tiempo que el padre Bernardo José Pellicer asía personalmente las riendas de la Provincia de Valencia. A ésta volverían también, pese a la opinión contraria del Consejo de Aragón ${ }^{87}$, los principales protagonistas de las inquietudes que la habían tenido en vilo durante meses. Así lo quiso Carlos II a petición del saliente comisario general, según informó a la más alta instancia seráfica

haviéndose logrado ya la tranquilidad en los mencionados disturbios mediante el çelo que havéis contribuido a esse fin y las providencias que, al mismo tiempo, mandé aplicar..., y haviendo juntamente mandado que, en consideración de haverse concluido estos negocios, a cuyo fenezimiento ha contribuido en mucha parte el dicho fray Antonio de Cardona, oy electo arçobispo de Valencia, se alzasse sin distincción alguna el impedimento a todos los que le tenían para entrar en Valencia por causa de las refe-

\footnotetext{
84 Ibidem, p. 448.

85 Ibidem, p. 450.

86 Archivo Segreto Vaticano (ASV), Archivio della Congregazione Concistoriale. Acta Camerarii, 25, ff. 1- 1v, y Processus Consistorialis, 94, ff. 243-264v.

87 Sólo en el caso del trinitario fray Juan Bautista Aguilar se mostró partidario el Consejo de levantarle el destierro, pues "aunque fue comprehendido en fomentar la turbación, ovedeció con resignación y puntualidad el real orden de vuestra magestad y así hizo mérito para que vuestra magestad le mande restituir a su residencia". Pero no a los padres Jaime Vitoria y Juan Bautista Todo, inobedientes hasta el final con el comisario general, "a cuyos preceptos se mostraron no reducirse". Como tampoco al canónigo Vicente Vitoria, el peor de todos los citados, para el que pedía " se le dilate más la mortificación que se le dio con su destierro, para que la demasiada benignidad no dé aliento a otros para que se cometan semejantes desahogos contra el sosiego público". ACA, Consejo de Aragón, Leg. 695, docs. 33 / 39-33 /40.
} 
ridas disensiones, atendiendo assimesmo a la súplica que, sobre esto, me hizo el dicho commissario general fray Antonio de Cardona, he resuelto avisaros el estado de esta dependencia para que lo tengáis entendido ${ }^{88}$.

Con ocasión de la Navidad de 1700, el ministro provincial de los franciscanos valencianos exhortaría a sus hermanos de hábito a olvidar rencores, restañar heridas y aunar fuerzas. Volvería a hacerlo en el definitorio reunido a comienzos del año entrante, en el que se dio lectura a un decreto del recientemente electo ministro general, fray Luis de la Torre, absolviendo al padre Jaime Vitoria de cuantas faltas se le habían atribuido ${ }^{89}$. Era un paso más hacia la definitiva normalización de la Provincia seráfica, a la que dedicaría fray Bernardo José Pellicer su gobierno poco antes de que la Guerra de Sucesión volviera a enmarañarlo todo por motivos bien distintos ${ }^{90}$.

\footnotetext{
88 Ibidem, doc. 33 / 52.

89 Martínez Colomer, op. cit. (nota 6), pp. 452-455.

90 PÉrez ApAricio, C.: "El clero valenciano a principios del siglo XVIII: la cuestión sucesoria", Estudios de Historia de Valencia (1978), pp. 252-274.
} 